\section{Contemporary Educational Researches Journal}

Volume 09, Issue 4, (2019) 103-109

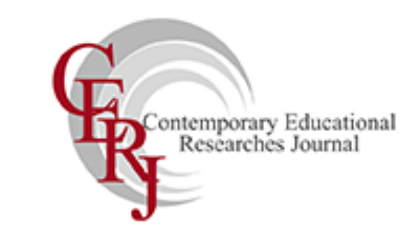

www.cerj.eu

\title{
Amateur sport and emotional burnout formation in high school students
}

Sergii Tukaiev*, Department of Physiology of Brain and Psychophysiology, Educational and Scientific Centre 'Institute of Biology and Medicine', National Taras Shevchenko University of Kyiv, 64/13, Volodymyrs'ka St., 01601 Kyiv, Ukraine; Laboratory on Theory and Methodic of Sport Preparation and Reserve Capabilities of Athletes, Scientific Research Institute, National University of Physical Education and Sports of Ukraine, 1, Fizkultury St., 03150, Kyiv, Ukraine

Olena Dolgova, Department of Aviation Psychology, Institute of the Humanities, National Aviation University of Kyiv, 1, Kosmonavta Komarova Av., 03680 Kyiv, Ukraine

Olena Lysenko, Laboratory on Theory and Methodic of Sport Preparation and Reserve Capabilities of Athletes, Scientific Research Institute, National University of Physical Education and Sports of Ukraine, 1, Fizkultury St., 03150, Kyiv, Ukraine

Svetlana Fedorchuk, Laboratory on Theory and Methodic of Sport Preparation and Reserve Capabilities of Athletes, Scientific Research Institute, National University of Physical Education and Sports of Ukraine, 1, Fizkultury St., 03150, Kyiv, Ukraine

Yurii Havrylets, Department of Social Communication, Institute of Journalism, National Taras Shevchenko University of Kyiv, 36/1, Melnikova Str., 04119, Kyiv, Ukraine

Volodymyr Rizun, Department of Social Communication, Institute of Journalism, National Taras Shevchenko University of Kyiv, 36/1, Melnikova Str., 04119, Kyiv, Ukraine

Tatyana Vasheka, Department of Aviation Psychology, Institute of the Humanities, National Aviation University of Kyiv, 1, Kosmonavta Komarova Av., 03680 Kyiv, Ukraine

Annemieke J. M. van den Tol, Faculty of Health and Life Sciences, School of Psychology, De Montfort University, Hawthorn Building, Leicester, LE1 7BH, United Kingdom

\section{Suggested Citation:}

Tukaiev, S., Dolgova, O., Lysenko, O., Fedorchuk, S., Havrylets, Y., Rizun, V., Vasheka \& Tol, A. (2019). Amateur sport and emotional burnout formation in high school students. Contemporary Educational Researches Journal. 9(4), 103-109. https://doi.org/10.18844/ceri.v9i4.4328

Received from April 21, 2019; revised from July 18, 2019; accepted from October 15, 2019

Selection and peer-review under responsibility of Assoc.Prof. Dr. Deniz Ozcan, Ondokuz Mayıs University, Turkey. ${ }^{{ }^{0}} 2019$ United World Center of Research Innovation and Publication. All rights reserved.

\footnotetext{
* ADDRESS FOR CORRESPONDENCE: Sergii Tukaiev , National Taras Shevchenko University of Kyiv, Educational and Scientific Centre "Institute of Biology and Medicine", Department of Physiology of brain and psychophysiology, 64/13, Volodymyrs'ka St., 01601 Kyiv, Ukraine, National University of Physical Education and Sports of Ukraine, Scientific Research Institute, Laboratory on Theory and Methodic of Sport Preparation and Reserve Capabilities of Athletes, 1, Fizkultury St, 03150, Kyiv, Ukraine

E-mail address: tukaev@univ.kiev.ua
} 


\begin{abstract}
Practicing sports, as well as physical activity in general, contribute to a healthy lifestyle, help to prevent numerous chronic diseases, and play a therapeutic role in addressing a number of cognitive and psychological disorders (such as depression, distorted body image and self-perception and low self-esteem). As regards students, freshmen with higher physical capabilities can better adapt to new college environment, which in turn influences their well-being, psychological state and ability to study. The aim of our study was to detect the level of emotional burnout and individual psychological characteristics of the university students, engaged in amateur sports. It was shown that the group of amateur sportsmen demonstrated higher level of arousal and mobility of neural processes, and lower level of neuroticism, lower level of neurotisation, anxiety, psychic tension and depression. This allows us to conclude that the type of nervous system may define the disposition toward the physical activity, and the strength of nervous system determines the ability to achieve success in sports. Our data indicate that practicing sports prevent the development of burnout, reduce the negative impact of daily emotional stress and provide a socially acceptable way to express aggression.
\end{abstract}

Keywords: Amateur sportsmen, burnout, typological and personality traits

\title{
1. Introduction
}

The sport activities and intense physical activities enhance a healthy lifestyle, form a human body's ability to recuperate, protect from injury and premature aging, allow one to be an effective worker or student able to succeed under extreme conditions, help prevent the development of many chronic diseases (cardiovascular disease, obesity, hypertension, etc.) and therapeutically foster the healing process in a number of cognitive and mental disorders (such as depression, anxiety, sensitivity to stress, emotional disorders, premenstrual syndrome, distorted perception of one's own body and distorted self-perception and low self-esteem) $(2,17,18)$. The positive impacts of moderate-intensity exercise on the improvement in one's subjective well-being, emotional state and mood are widely known $(1,7,8,25)$. Physical activities and regular exercising foster the healing processes in some mental disorders such as depression, anxiety, fear and stress $(1,15,23)$.

In the present study, we focused on the amateur sport as a basis for emotional burnout coping response and mental differences in university athletes engaged in amateur sports and non-athletes as an indicator of willingness to physical activities.

In sports psychology, the problem of burnout is extremely widespread $(4,5,6,9,10,14,21,30)$. Most of athlete burnout studies have focused researcher's attention on elite and high performing adult and adolescent athletes (elite Canadian athletes (12), rugby players $(4,5)$, table tennis players (13), soccer players $(14,28)$ and handball players $(11))$. However, the studies of burnout among amateur athletes, especially at higher levels, are scarce (5). Goodger et al. 2007; $2010(9,10)$ and Wylleman \& Lavallee (2004) (30) noted in the reviews that the most studies focused on psychological, demographic and situational factors causing burnout. Athlete burnout is mainly caused by poor coping behaviour and problem-solving skills (21). In the context of sports, the consequences of burnout do impact not only health and well-being but also the performance of athletes (9). Stress and burnout have the greatest impact on the future performance of young athletes due to possible reduction in their sense of accomplishment (13).

Several models to describe the development of burnout in athletes were created. Many theories are focused on the distinguishing burnout from overtraining and fatigue (9). Smith's cognitiveaffective model of athlete burnout suggests that burnout is the result of chronic stress and is developing simultaneously with stress. Burnout is associated with contextual factors in reference to the cognitive assessment of the connection between an individual and situation, physiological reactions (related to an assessment) and behavioural reactions. These components of burnout depend on the motivational and personal factors (9). According to Coakley (1992) (3), the starting point of 
burnout in young athletes is in the social arrangement of professional sports, namely self-identity and self-control issues. In the commitment-based model of Schmidt and Stein, burnout is not just a response to stress, but it is a factor associated with an athlete's commitment to competitions. This is reflected in the following statement: I 'have to be' rather than I 'want to be'. Silva's model is based on burnout as a result of continuous overtraining and negative responses to disadaptation to training (9).

In the aetiology of stress among professional sportsmen and amateurs, there is a complex system of interacting variable factors such as the environment, a personality of an athlete and stressful events (16). There were demonstrated that the main determinants of individual and typological indicators of burnout are high levels of neuroticism, introversion as well as weak processes of excitation and inhibition and low mobility of nervous processes (19).

\subsection{Purpose of research}

The purpose of this study is to determine the level of emotional burnout of individuals among those practicing amateur sports and to determine mental differences in university athletes engaged in amateur sports and non-athletes.

\subsection{The hypotheses}

- Regular practicing amateur sports improve emotional state of students and lead to emotional burnout decrease;

-Typological features of students affect their disposition to practicing amateur sports.

\section{Methods of Research}

\subsection{Participants}

Three hundred forty-eight healthy volunteers participated in the study. Participant sample comprised $1^{\text {st }}$-year students who studied 'Psychology' at the Taras Shevchenko National University of Kyiv, Ukraine. The participants were eligible to enroll in the study if they were $\geq 18$ years old and had no clinical manifestations of mental or cognitive impairment. Exclusion criteria were as follows: The prior use of psychoactive medication, drug or alcohol addiction and psychiatric or neurological complaints. The study was approved by the Bioethics Commission of Educational and Scientific Centre 'Institute of Biology and Medicine', Taras Shevchenko National University of Kyiv, in accordance with the World Medical Association Declaration of Helsinki - ethical principles for the medical research involving human subjects (Helsinki, Finland, June 1964). Each participant filled out written informed consent. All volunteers participated in the study for course credits. All participants were tested 1-3 months before the exam time (baseline session). Amateur sportsmen group included 67 persons (33 males and 34 females, aged $17-23$ years old, $M_{\text {age }}=18$ and $S D=1.57$ ) who exercised regularly participating in team sports (football and volleyball) and individual sports (running and swimming) and had sports experience from 2 to 7 years spending 4-8 h/week training. Among the psychology students, the number of individuals having no experience in sports was much higher than the number of those practicing sports. The control group of non-athletes included 281 students (220 women and 61 men aged $18-23$ years old, $M_{\text {age }}=18$ and $S D=1.24$ years) with no prior sports experience except physical education classes at school and university.

\subsection{Psychometric tools}


The psychodiagnostic questionnaire, filled out by the participants, was divided into two parts.

1) To measure the severity of emotional burnout in students, we used the 22-item Maslach Burnout Inventory (MBI) and 84-item Boyko's syndrome of emotional burnout (SEB) inventory (29) adapted for students by Tukaiev and Vasheka (27).

The burnout syndrome in professional athletes is related to excess demands imposed by training, competition and performance (20). There are special the Soccer Officials' Stress Survey (24) and the Athlete Burnout Questionnaire (ABQ) (20) that focus on sport. Using these inventories, we did not specifically measure university athletes' educational burnout. It should be noted that athlete burnout mediates by self-determined motivation $(12,14)$. Earlier, we showed that motivational, semantic and communicative sphere of students determine the formation of the SEB during the studying $(26,27)$. We assumed that both questionnaires (the Soccer Officials' Stress Survey and the ABQ), as opposed to $\mathrm{MBI}$ and $\mathrm{SEB}$, are not appropriate for investigating burnout in the amateurs as the predictors of burnout are beyond the sports field.

2) To investigate the personality characteristics and mental health, we have used the following psychometric techniques (22). We used the Temperament Diagnostics Test by Jan Strelau and EPI Test by Hans Eysenck to study the individual typological characteristics. These methods allowed for determining the strength of excitation and inhibition processes, mobility of nervous processes, tranquillity of one's nervous system and the level of extraversion-introversion and neuroticism. Besides, to determine the mental state, stress resistance of the participants, the following tests were used: Boston Stress-Resistance Test and Lemur-Tessier-Fillion psychological stress measure (PSM-25).

\subsection{Data analysis}

We carried out statistical data processing involving mathematical statistical methods (the nonparametric Mann-Whitney U-test and Student's t-test to determine differences between the groups) (StatSoft STATISTICA 64, version 10.0.1011.0). In addition, we used the Kolmogorov-Smirnov test to determine the type of data distribution. The differences were considered significant at $p<0.05$.

\subsection{Results and discussion}

Can practicing sports protect one against stress? This question is hard to answer regarding prior research (23). Regarding the effect of exercise training on psychosocial and physiological reactivity on subsequent psychological stressors such as complex cognitive tasks or public speaking, there is lack of evidence. With this in mind, we can assume that the above-mentioned effect has not been able to be considered entirely positive yet. Our data enable us to conclude that amateur sport activities help cope with the consequences of stress, strengthen stress resistance and positively influence coping with stress in general. The positive impact of sports on emotional processes is confirmed by the StateTrait Anxiety Inventory and the Manifest Anxiety Scale. We observed lower levels of anxiety in a group of sport amateurs (in both examined groups of students, the level of state-trait anxiety is middle), lower levels of neurotisation, psychic tension and depression.

Table 1. Typological features: Group difference according to Temperament Diagnostics Test by J.

Strelau and EPI Test by H. Eysenck in examined groups of students

Indices

Group average

Amateur sportsmen
Non-athletes group
Confidence level of group

difference $(p)$ 
group

\begin{tabular}{cccc}
\hline Strength of excitation & $65.6 \pm 11.9$ & $59.3 \pm 10.7$ & 0.01 \\
\hline Mobility of nervous processes & $61.5 \pm 8.8$ & $57.8 \pm 9.6$ & 0.05 \\
\hline Neuroticism & $11.6 \pm 3.7$ & $13.3 \pm 3.5$ & 0.05
\end{tabular}

As expected, amateur sportsmen have lower levels of sensitivity to stress in comparison with the ones from the non-athletes group. This might be explained by higher levels of strength of excitation and inhibition among the sportsmen (57 is an average coefficient for both groups). The data obtained during the study showed that the group of amateurs had a higher level of excitation and mobility of nervous processes (Table 1). Given the priority that was attributed to the between-groups detection differences and the detection of casual parameters was postponed, we can only surmise that the type of one's nervous system is a platform to predict a tendency to perform physical activities. The strength of one's nervous system allows one to successfully attain goals in a chosen sport, which, in turn, supports the motivation to get involved in sport activities.

Table 2. Indices of psychoemotional states of examined groups of students

\begin{tabular}{llll}
\hline Indices & \multicolumn{2}{l}{ Group average } & $\begin{array}{l}\text { Confidence level of } \\
\text { group difference }(p)\end{array}$ \\
\cline { 2 - 4 } & $\begin{array}{l}\text { Amateur sportsmen } \\
\text { group }\end{array}$ & Non-athletes group & 0.003 \\
\hline Psychic tension (PSM-25) & $72 \pm 23,5$ & $86.5 \pm 21.5$ & 0.005 \\
\hline $\begin{array}{l}\text { Stress resistance } \\
\text { (inverse scale) }\end{array}$ & $40.4 \pm 6.1$ & $44.6 \pm 6.6$ & \\
\hline
\end{tabular}

Considering amateur athletes' lower sensitivity to stress (Table 2), their level of burnout could be expected to be low too. Emotional burnout is a form of job stress that leads to serious consequences for society and organisations, as well as for interpersonal and family relations due to mental and behavioural changes of different severity. It is an acquired stereotype of one's emotional behaviour, more often professional behaviour, which can be determined as professional deformation of an individual (29). An expectation gap, which occurs in case of a disagreement between the expectations and a real-life situation, can influence development of burnout. High motivation to perform an activity can protect against burnout, while one's predisposition to find an excuse for failure outside, or confer responsibility other people around one in any activities, learning and sport heavily aggravate the formation of burnout $(26,27)$.

Table 3. The intensity of burnout observed in examined groups of students

\begin{tabular}{|c|c|c|c|}
\hline \multirow[t]{3}{*}{ Indices } & \multicolumn{2}{|l|}{ Group average } & \multirow{3}{*}{$\begin{array}{l}\text { Confidence level of } \\
\text { group difference }(p)\end{array}$} \\
\hline & $\begin{array}{l}\text { Amateur sportsmen } \\
\text { group }\end{array}$ & Non-athletes group & \\
\hline & \multicolumn{2}{|c|}{ Data according to Maslach Burnout Inventory } & \\
\hline Emotional exhaustion phase & $20.4 \pm 5.1$ & $23.3 \pm 5.5$ & 0.04 \\
\hline $\begin{array}{l}\text { Lack of personal accomplishments } \\
\text { phase }\end{array}$ & $33.4 \pm 5.5$ & $30.5 \pm 4.9$ & 0.05 \\
\hline \multicolumn{4}{|c|}{ Data according to the test by Boyko } \\
\hline Dissatisfaction by oneself & $4.5 \pm 3.6$ & $6.1 \pm 4.3$ & 0.05 \\
\hline Anxiety and depression & $6.1 \pm 5.4$ & $9.0 \pm 6.6$ & 0.039 \\
\hline Anxiety Tension stage & $18.7 \pm 14.8$ & $25.5 \pm 16$ & 0.046 \\
\hline Emotional and moral disorientation & $8.8 \pm 4.9$ & $10.8 \pm 4.8$ & 0.015 \\
\hline $\begin{array}{l}\text { Psychosomatic and } \\
\text { psychovegetative impairments }\end{array}$ & $3.86 \pm 3.8$ & $6.16 \pm 4.5$ & 0.027 \\
\hline
\end{tabular}




\begin{tabular}{llll}
\hline Exhaustion stage & $28.8 \pm 13.3$ & $35 \pm 15.8$ & 0.045 \\
\hline
\end{tabular}

The results of this study allow us to conclude that the level of burnout among amateur sportsmen is lower than among the non-athletes. As expected, practicing amateur sports help prevent emotional burnout in students. The data support the initial assumption that the group of amateur sportsmen has less pronounced symptoms of burnout in comparison to those who do not practice any sport. However, the index of the personal achievement reduction was more significant in the group of athletes, which may be explained by possible disappointment in studying activities and dissatisfaction with achievements in sports. Despite this single exception, one may conclude that practicing sports have a strong positive impact on the emotional and mental state of a person, protect an individual from stress factors, help athletes cope with difficulties and bring harmony to one's physical and mental life (Table 3).

\section{Conclusions}

A sufficient level of physical activity is a necessary component of a healthy lifestyle. Unfortunately, the number of university athletes in Ukraine equals to only $30 \%$. Various individual psychological and typological characteristics have been revealed in the group of sport amateurs and in the comparison group. Amateur sportsmen have a higher level of excitation and mobility of nervous processes and less marked neuroticism and such emotional traits as anxiety, depression and mental stress. In our opinion, low sensitivity to stress among interviewees practicing amateur sports results in decrease of emotional burnout. This distinguishes amateur sportsmen from professional sportsmen, where athletes are more sensitive to stress, and the intensity of their emotional burnout is higher. The data obtained during the study support the assumption that amateur sports positively influence mental and physiological state of an individual.

\section{Competing Interest}

The authors declare that they have no competing interest.

\section{References}

Biddle, S. J., Fox, K. R., Boutcher, S. H., \& Faulkner, G. E. (2001). The way forward for physical activity and the promotion of psychological well-being (154-168). Routledge: Physical Activity and Psychological Well-being.

Bize, R., Johnson, J. A., \& Plotnikoff, R. C. (2007). Physical activity level and health-related quality of life in the general adult population: A sxystematic review. Preventive Medicine, 45(6), 401-415.

Coakley, J. (1992). Burnout among adolescent athletes: A personal failure or social problem? Sociology of Sport Journal, 9(3), 271-285.

Cresswell, S. L., \& Eklund, R. C. (2005a). Motivation and burnout in professional rugby players. Research Quarterly for Exercise and Sport, 76(3), 370-376.

Cresswell, S. L., \& Eklund, R. C. (2005b). Motivation and burnout among top amateur rugby players. Medicine and Science in Sports and Exercise, 37(3), 469-477.

DeFreese, J. D., Raedeke, T. D., \& Smith, A. L. (2015). Athlete burnout: an individual and organizational phenomenon. In J. M. Williams, \& V. Krane (Eds.), Applied sport psychology: Personal growth to peak performance (7th ed., pp. 444-461). New York, NY: McGraw-Hill.

Edwards, S. (2006). Physical exercise and psychological well-being. South African Journal of Psychology, 36(2), 357-373.

Fox, K. R. (1999). The influence of physical activity on mental well-being. Public Health Nutrition, 2(3a), 411-418.

Goodger, K., Gorely, T., Lavallee, D., \& Harwood, C. (2007). Burnout in sport: A systematic review. The Sport Psychologist, 21(2), 127-151. 
Tukaiev, S., Dolgova, O., Lysenko, O., Fedorchuk, S., Havrylets, Y., Rizun, V., Vasheka \& Tol, A. (2019). Amateur sport and emotional burnout formation in high school students. Contemporary Educational Researches Journal. 9(4), 103-109. https://doi.org/10.18844/cerj.v9i4.4328

Goodger, K., Lavallee, D., Gorely, T., \& Harwood, C. (2010). Burnout in sport: Understanding the process from early warning signs to Individualized Intervention. In: J. M. Williams (Ed.) Applied sport psychology: Personal growth to peak performance (6 $6^{\text {th }}$ ed., pp. 492-511). Columbus, OH (USA): McGraw Hill.

Isoard-Gautheu, S., Guillet-Descas, E., Gaudreau, P., \& Chanal, J. (2015). Development of burnout perceptions during adolescence among high-level athletes: A developmental and gendered perspective. Journal of Sport and Exercise Psychology, 37(4), 436-448.

Lonsdale, C., Hodge, K., \& Rose, E. (2009). Athlete burnout in elite sport: A self-determination perspective. Journal of Sports Sciences, 27(8), 785-795.

Martinent, G., \& Decret, J. C. (2011). Burnout, stress and recovery as predictors of performance: A longitudinal study among youth international table tennis players. International Journal of Table Tennis Sciences, 7, 78-79. Retrieved from http://www.24.137.199.140/ittf_science/SSCenter/docs/18-51\%20Martinent.pdf.

Martínez-Alvarado, J. R., García, F.G., \& Feltz, D. (2016). Athletes' motivational needs regarding burnout and engagement. Revista de Psicología del Deporte, 25(1), 65-71. Retrieved from http://www.ddd.uab.cat/pub/revpsidep/revpsidep_a2016v25n1/revpsidep_a2016v25n1p65.pdf.

Mehrabian, A. (1996). Pleasure-arousal-dominance: A general framework for describing and measuring individual differences in temperament. Current Psychology, 14(4), 261-292.

Miller, T. W., Vaughn, M. P., \& Miller, J. M. (1990). Clinical issues and treatment strategies in stress-oriented athletes. Sports Medicine, 9(6), 370-379.

Paluska, S. A., \& Schwenk, T. L. (2000). Physical activity and mental health. Sports Medicine, 29(3), 167-180.

Powell, K. E., Paluch, A. E., \& Blair, S. N. (2011). Physical activity for health: What kind? How much? How intense? On top of what? Annual Review of Public Health, 32, 349-365.

Radchuk, O., Tukaiev, S., Krizhanovskiy, S., \& Vasheka, T. (2012, January). Typological and personal determinants of burnout in students. In: International journal of psychology (Vol. 47) (pp. 603-603). ???: Wiley.

Raedeke, T. D., \& Smith, A. L. (2001). Development and preliminary validation of an athlete burnout measure. Journal of Sport and Exercise Psychology, 23(4), 281-306.

Raedeke, T. D., \& Smith, A. L. (2004). Coping resources and athlete burnout: An examination of stress mediated and moderation hypotheses. Journal of Sport and Exercise Psychology, 26(4), 525-541.

Raigorodsky, D. Y. (2011). Prakticheskaya psihodiagnostika. Metodiki i testy [Practical psychodiagnostics. Methodology and tests]. Moscow: Bahrah-Moscow.

Scully, D., Kremer, J., Meade, M. M., Graham, R., \& Dudgeon, K. (1998). Physical exercise and psychological well being: A critical review. British Journal of Sports Medicine, 32(2), 111-120.

Taylor, A. H., \& Daniel, J. V. (1987, April). Sources of stress in soccer officiating: An empirical study. In: Science and football: Proceedings of the first world congress of science and football (pp. 538-544). England: Routledge.

Thøgersen-Ntoumani, C., \& Fox, K. R. (2005). Physical activity and mental well-being typologies in corporate employees: A mixed methods approach. Work and Stress, 19(1), 50-67.

Tukaiev, S. V., Vasheka, T. V., \& Dolgova, O. M. (2013). The relationships between emotional burnout and motivational, semantic and communicative features in psychology students. Procedia-Social and Behavioral Sciences, 82, 553-556.

Tukaiev, S. V., Vasheka, T. V., \& Zyma, I. G. (2013). Psychological and neurophysiological aspects of the emotional burnout development. In V. P. Volkoff (Ed.), Actual aspects of internal medicine (pp. 86-107). Novosibirsk: SibAK.

Verardi, C. E. L., Nagamine, K. K., Domingos, N. A. M., De Marco, A., \& Miyazaki, C. (2015). Burnout and pre-competition: A study of its occurrence in Brazilian soccer players. Revista de Psicología del Deporte, 24(2), 259-264. Retrieved from http://www.redalyc.org/pdf/2351/235141413008.pdf.

Vodopyanova, N. E., \& Starchenkova, E. S. (2009). Syndrome of burnout: diagnostics and prevention (p. 336). SPb: Piter.

Wylleman, P., \& Lavallee, D. (2004). A developmental perspective on transitions faced by athletes. In M. R. Weiss (Ed.), Developmental sport and exercise psychology: A lifespan perspective (pp. 503-523). Morgantown, WV, US: Fitness Information Technology. 